\title{
Biochemical and biophysical alterations of the 7S and NC1 domain of collagen IV from human diabetic kidneys
}

\author{
H.-M. Raabe ${ }^{1}$, J.-H. Höpner ${ }^{2}$, H. Notbohm ${ }^{2}$, G.H. G. Sinnecker ${ }^{1}$, K. Kruse ${ }^{1}$, P. K. Müller ${ }^{2}$ \\ ${ }^{1}$ Klinik für Pädiatrie, Medizinische Universität zu Lübeck, Lübeck, Germany \\ ${ }^{2}$ Institut für Medizinische Molekularbiologie, Medizinische Universität zu Lübeck, Lübeck, Germany
}

\begin{abstract}
Summary Glycation of basement membrane collagen IV has been implicated as a major pathogenetic process leading to diabetic microvascular complications. To evaluate the relevance of carbohydrate-induced modifications on collagen IV in diabetic nephropathy, we isolated the cross-linking domains $7 \mathrm{~S}$ and NC1 from the glomerular basement membrane (GBM) of patients with diabetes mellitus. Modifications characteristic for glycated proteins were identified when the domains from diabetic kidney were compared with the same domains from human placenta as an unmodified control. In both domains a marked formation of inter-and intramolecular cross links could be demonstrated by SDS-PAGE. Further-
\end{abstract}

more circular dichroism studies showed a decrease in helicity of the 7S domain from human diabetic kidneys of $13 \%$, indicating denaturation already at room temperature. Thermal transition profiles, showing a shift of the denaturation temperature towards a lower temperature, with loss of a distinct second melting point, confirmed this observation. Our data provide further evidence for a possible role of protein-modification by glycoxidative reactions in the onset of diabetic nephropathy in vivo. [Diabetologia (1998) 41: 1073-1079]

Keywords Circular dichroism, collagen IV, diabetes, glycation, nephropathy.
Glycation and glycoxidative reactions have been recognised to be a major pathogenetic principle for biochemical and biophysical alterations of proteins in diabetes mellitus [1-3]. Both processes have been shown to increase in humans with age and even more in patients with diabetes mellitus with the duration of the disease [4-8].

Glycoxidative reactions, e.g. the Maillard reaction, are initiated by the condensation of a reducing sugar with an $\varepsilon$-amino group of lysyl- or hydroxylysyl-residues of proteins [9]. The resulting Schiff-base is stabilised subsequently by Amadori rearrangement and processed further in very diverse and not yet fully

Received: 7 January 1998 and in revised form: 16 April 1998

Corresponding author: Dr. J.-H. Höpner, Institut für Medizinische Molekularbiologie, Medizinische Universität zu Lübeck, Ratzeburger Allee 160, 23538 Lübeck, Germany

Abbreviations: GBM, Glomerular basement membrane; CD, circular dichroism elucidated chemical reactions resulting in a variety of cross-linked compounds. Only a small number of those, including pentosidine, have been characterised in structure and chemical composition [2, 10-16]. Glycation of proteins is associated with the formation of high-molecular aggregates that are stabilised by non-reducible cross-linking components [13, 17-18] with characteristic fluorescence spectra $[6,19,20]$. Circular dichroism (CD) spectroscopy studies of glycated proteins exhibited a damaging effect of the modifications on protein structure and stability [21, 22].

In diabetic nephropathy the disordered morphology and functional deficiency of the glomerular basement membrane (GBM) has been explained by glycation of the collagen IV network providing the mechanical scaffold of the membrane texture. Collagen IV monomers consist of a collagenous major triplehelical domain with two specific cross-linking domains, the $\mathrm{NC} 1$ domain at the C-terminal end and the $\mathrm{N}$-terminus the $7 \mathrm{~S}$ domain [23-26], facilitating 
the aggregation of collagen IV-monomers to a large, chicken-wired network by a highly specific interaction [27-29].

An influence of glycation of collagen IV and other integral proteins of GBM on their functional properties, e.g. collagen-network formation [30], basement membrane architecture [31] and binding of physiological and non-physiological ligands [32-35] has been shown by several in vitro and in vivo studies.

The effects of carbohydrate-induced reactions in vitro on two distinct domains of collagen IV (7S domain and $\mathrm{NC1}$ domain) have been reported recently [22]. Our study was aimed to describe biochemical and biophysical properties of the collagen IV crosslinking domains 7S and $\mathrm{NC1}$ from human kidneys obtained from patients with diabetes mellitus Type II. By comparison with native domains isolated from human placental basement membrane it became evident that glycoxidative modifications in diabetic nephropathy may have a decisive role in both the onset and progression of the disease.

\section{Materials and methods}

Extraction of the collagen IV cross-linking domains $7 S$ and NC1 from human placenta and from human kidneys from patients with long-standing diabetes mellitus. Tissue from kidneys of three patients with diabetes mellitus Type II who had had the disease longer than 10 years was obtained from autopsies at the department of pathology after consent of the patient had been obtained in advance. The glomeruli were isolated from homogenized kidneys by sequential sieving. The GBM was then prepared by ultrasonic degradation of the glomeruli [36]. Normal human placental tissue was received from the department of Obstetrics and Gynaecology at the University of Lübeck and served as native control tissue. The $7 \mathrm{~S}$ domain and the NC1 domain were prepared according to Weber et al. [26]. Briefly, 7S and NC1 were isolated by two consecutive collagenase digests (collagenase A, Boehringer Mannheim, Mannheim, Germany) of Guanidinium-hydrochloride (Sigma, Deisenhofen, Germany) extracted human placental membranes and human GBM, followed by molecular sieve chromatography on a superose 12 resin (Phamacia, Freiburg, Germany). The identity of both the $7 \mathrm{~S}$ domain and the NC1 domain was shown by SDS-PAGE and immunoblotting using suitable antibodies.

Electrophoresis. SDS-PAGE was performed on slab gels [37] using $4 \%$ stacking and $10 \%$ separation gels. After electrophoretic separation gels were stained with Coomassie blue.

Immunoblotting. Electrophoretically separated proteins were transferred from SDS-PAGE-gels to nitrocellulose sheets (Schleicher and Schüll, Germany) using a protocol for semidry blotting [38]. The 7S and the NC1 domain were marked with specific antibodies from our own laboratory and stained by a colour reaction initiated by a second horseradish peroxidasecoupled antibody (DAKO, Germany).

Fluorimetric analyses. Fluorescence spectra were measured at an excitation wavelength of $335 \mathrm{~nm}$ and $370 \mathrm{~nm}$. Fluorescence was determined for emission spectra from $370 / 400 \mathrm{~nm}$ to 500



Fig. 1. 6\% SDS-PAGE of 7S from human placenta (lane 1 and 3 ) and human diabetic kidney (lane 2 and 4) marker, non-collagenous protein (lane 5) lane 1-2: reducing conditions (addition of $20 \%$ mercaptoethanol to sample buffer) lane 3-5: non-reducing conditions

nm. Readings were obtained with a Perkin Elmer Luminescence Spectrometer LS 50 B. The fluorescence was normalised to the protein content of the sample as determined by dry weight measurement.

Circular dichroism and transition profiles of the $7 S$ domain. CD spectra were recorded on a Jasco J-500A spectropolarimeter equipped with a temperature-controlled quartz cell of $1 \mathrm{~cm}$ length (Gilford, Oberlin, USA). For transition curves conversion to random coil corresponds to the ellipticity at $95^{\circ} \mathrm{C}$, typical for totally denatured collagen IV. Thermal transition curves were recorded at a fixed wavelength of $221 \mathrm{~nm}$ while the temperature of the sample was linearly raised at a rate of $25^{\circ} \mathrm{C} / \mathrm{h}$ using a temperature programmer (Gilford). Helicity was expressed as the per cent of the value at room temperature. It was defined to be $100 \%$ at room temperature and $0 \%$ at $95^{\circ} \mathrm{C}$. The sample concentration was $100 \mu \mathrm{g} / \mathrm{ml}$ in $0.05 \%$ acetic acid. A change of thermal stability due to radiation damage could not be detected. The statistical error at $221 \mathrm{~nm}$ for one measurement was calculated to be $5 \%$ of the ellipticity.

\section{Results}

Extraction of $7 S$ and NC1 from human kidney and placenta and demonstration of intramolecular and intermolecular cross-links. SDS-PAGE of the $7 \mathrm{~S}$ domain from human placenta and kidneys from patients with long-standing diabetes mellitus was performed under reducing and non-reducing conditions. In our preparation from both tissues the 7S domain existed in both the long $(360 \mathrm{kD})$ and the short form $(250$ $\mathrm{kD})$. The domain from diabetic kidneys showed nonreducible cross-links (Fig. 1), while most of the native $7 \mathrm{~S}$ domain from human placenta was separated into 


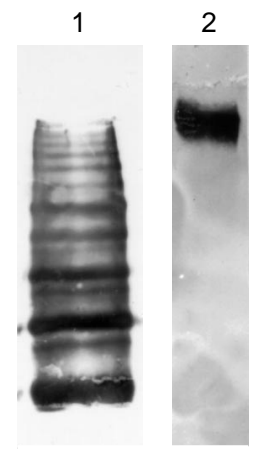

Fig. 2. Western Blotting of a $6 \%$ SDS-PAGE of $7 \mathrm{~S}$ from human placenta (lane 1) and human diabetic kidney (lane 2) under reducing conditions (addition of $20 \%$ mercaptoethanol to sample buffer)

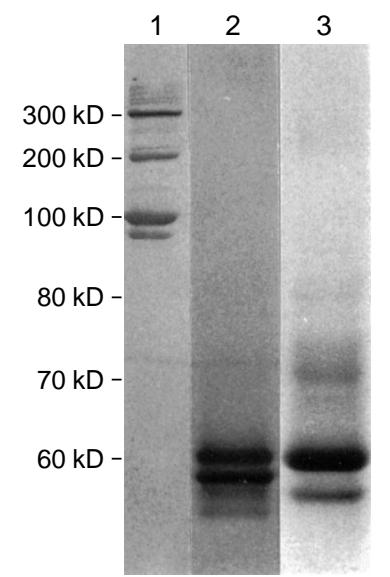

Fig. 3. $10 \%$ SDS-PAGE of the NC1 domain from human placenta (lane 2) and human diabetic kidney (lane 3). Molecular weight-standard (collagen I) with bands at $300 \mathrm{kD}, 200 \mathrm{kD}$ and $100 \mathrm{kD}$ (lane 1)

oligomers ranging in size from $180-\mathrm{kD}$ under reducing conditions [25]. In contrast, hardly any oligomers could be seen in the fraction from diabetic kidney, similar to what has been described earlier for the in vitro glycated 7S domain [21]. Western blotting with anti-7S-antibody confirmed the identity of the 7S domain (Fig. 2).

The typical gel electrophoretic pattern with a double band at $60 \mathrm{kD}$ was found for the $\mathrm{NC1}$ domain. SDS-PAGE and Western blotting of the NC1 domain from diabetic kidney showed the formation of highmolecular weight material (Fig. 3 and 4) with additional bands at molecular weights of $70 \mathrm{kD}, 80 \mathrm{kD}$ and $100 \mathrm{kD}$ besides the normal double band at 60 $\mathrm{kD}$. These high molecular weight bands showed a positive staining with anti-NC1 antibodies and represent $\mathrm{NC} 1$ trimers and tetrameres.

Detection of cross-links by fluorescence. Cross-link formation in both domains was also shown by increased fluorescence at two specific excitation wave-

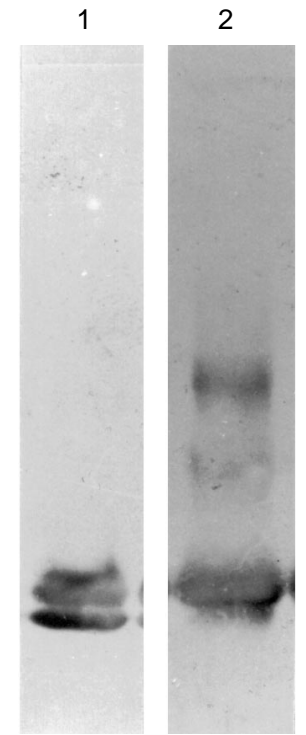

Fig. 4. Western Blotting of a $10 \%$ SDS-PAGE of the NC1 domain from human placenta (lane 1) and human diabetic kidney (lane 2)

lengths. Excitation at $335 \mathrm{~nm}$ showed a marked increase in the pentosidine-like fluorescence [13] at $385 \mathrm{~nm}$ for both domains from diabetic kidney. Emission at 440-nm upon excitation at $370 \mathrm{~nm}$ ("collagenlinked fluorescence" [34]) is increased 12-fold (7S) and 78 -fold ( $\mathrm{NC1}$ ), respectively, in protein from the diabetic organ.

Conformation and thermal stability of the $7 S$ domain. To assess the effect of glycation in vivo on triple-helical conformation the collagenous 7S domain was examined by $\mathrm{CD}$-spectroscopy. For the native $7 \mathrm{~S}$ domain the spectrum was in good agreement with that reported previously [25]. In contrast, the 7S domain from diabetic kidney showed a decrease in helicity of $13 \%$ in relation to control measured by the difference between the signals at $221 \mathrm{~nm}$ for the domain at room temperature and at $95^{\circ} \mathrm{C}$. Unlike the spectrum for $7 \mathrm{~S}$ domain from human placenta the signal at $221 \mathrm{~nm}$ for the protein from human diabetic kidney after thermal degradation at $95^{\circ} \mathrm{C}$ did not disappear completely (Fig. 5).

Thermal transition profiles were recorded to detect a possible influence of glycation on the stability of the $7 \mathrm{~S}$ domain. For the $7 \mathrm{~S}$ domain from human placenta we showed a melting profile with two distinct melting points as described previously by Ristelli et al. [25]. Our recordings, however, showed the second melting point to be at a higher temperature $\left(80^{\circ} \mathrm{C}\right.$ vs $72^{\circ} \mathrm{C}$ as measured by Ristelli et al.). The melting profile of the $7 \mathrm{~S}$ domain from diabetic kidneys followed the profile of the control until the first melting point was reached. Beyond that temperature the degree of helicity decreased steadily and did not level off in a plateau. At $65^{\circ} \mathrm{C}$ the degree of helicity 

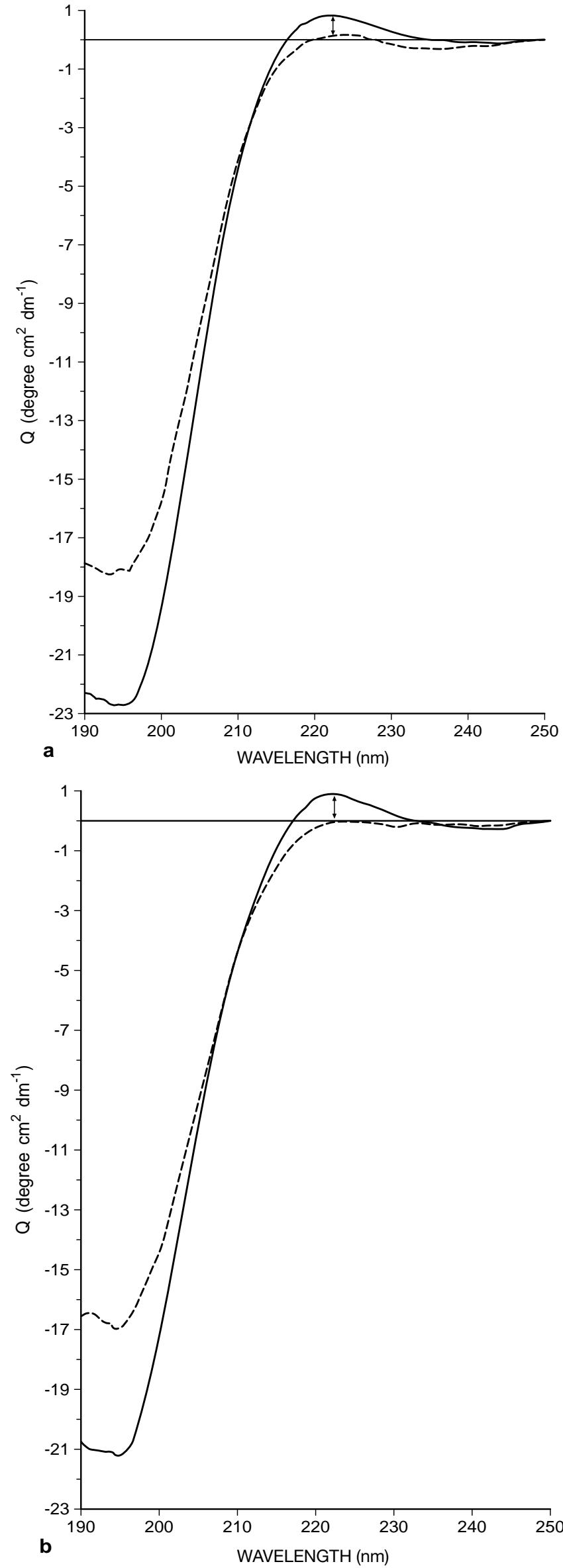

was $50 \%$, whereas it was markedly higher in the $7 \mathrm{~S}$ domain from human placenta (Fig.6).

\section{Discussion}

The notion that hyperglycaemia is the major pathogenic feature for the long-term sequelae of diabetes mellitus is widely accepted $[2,39]$. Diabetic nephropathy is the most important complication with a cardiovascular mortality 37 times higher than that of the general population [40].

In addition to the characteristic histological findings in diabetic nephropathy specific alterations have been found in basement membrane glycoproteins from diabetic patients [31, 41-43]. Functional impairment of the carboxyterminal domain of collagen IV in interacting with the major triple-helical domain has been shown earlier [30]. To find additional evidence for the impact of altered cross-linking domains of collagen IV for the pathogenesis of diabetic nephropathy, we investigated the effects of longstanding diabetes mellitus on the 7S domain and the $\mathrm{NC} 1$ domain of collagen IV isolated from the GBM.

In line with recent observations derived from in vitro glycation experiments our study shows that the domains from collagen IV of diabetic GBM may be the target of cross-link mechanisms in a diabetic metabolic state. These cross-links were not destroyed by heat nor were they susceptible to reducing agents ( $5 \mathrm{~min}$ at $95^{\circ} \mathrm{C}$ in the presence of mercaptoethanol). For the NC1 domain we were able to indicate the presence of cross-linking by showing trimers (highmolecular weight material at $90 \mathrm{kD}$ ) and tetrameres (high-molecular weight material at $110 \mathrm{kD}$ ). These aggregates cannot found be in native tissue [30,44].

A second line of evidence for cross-linking of collagen IV domains from kidneys of patients with diabetes mellitus was obtained by fluorescence spectroscopy. Fluorophores typical for glycated proteins form on both the 7S and the $\mathrm{NC1}$ domain. On the NC1 domain they can be found to a greater extent than on the 7S domain probably because of its higher content in arginyl- and lysyl residues [25, 26].

There was, however, no appreciable change either in the amino acid composition or in the content of the hydroxylyslyl-bound glycosides when glycated

Fig.5a,b. Circular dichroism spectra of the 7S domain from (a) kidneys of patients with diabetes mellitus and (b) human placenta (as native control) at room temperature [-] and after thermal denaturation $\left(30 \mathrm{~min}\right.$ at $\left.95^{\circ} \mathrm{C}\right)$ [---]. Arrows display the difference in ellipticity between normal and thermally degraded $7 \mathrm{~S}$ domain. For 7S-domain from kidneys of patients with diabetes mellitus the difference is only $87 \%$ of the value for the control 


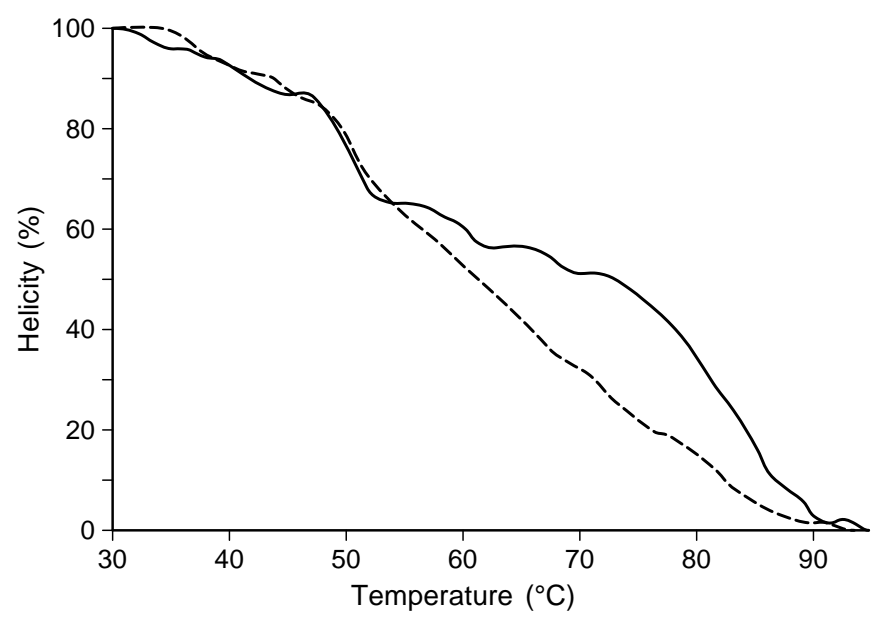

Fig. 6. Melting profiles of the $7 \mathrm{~S}$ domain from kidneys of patients with diabetes mellitus [--] and human placenta (as native control) [-] recorded with circular dichroism at $221 \mathrm{~nm}$

and non-glycated domains were analysed (data not shown). This effect which had been observed earlier by Trueb et al. [45] could in part reflect problems with the extraction of proteins from modified tissue. The sensitivity of amino acid analysis may be too low to detect the subtle changes expected in the amino acid composition of the modified domains.

Formation of cross-links, however, had an impact on collagen triple helix stability and this has been shown previously for collagen II from intervertebral discs of elderly patients [22]. Our experiments indicated a denaturation with loss of the triple-helicity of the 7S domain already at room temperature. Melting profiles confirmed this observation showing a lower thermal stability for the glycated $7 \mathrm{~S}$ domain with a shift of the second part of the melting profile (reflecting denaturation of the central part of the domain) towards higher temperature. Thus it seems likely that the cross-linking modifications that altered the conformational stability of the protein are located in the central part of the molecule. In vitro glycated $7 \mathrm{~S}$ domain, however, investigated in a recent study failed to show the detrimental effects at room temperature [21], indicating that glycation of proteins in vivo and in vitro may follow different pathways.

The ideal control for studies on in vivo modified proteins would be a native domain from the same species and the same tissue. In our study we chose a native domain from human placenta as a readily available tissue. The triple-helical collagen IV molecule is composed of three $\alpha$-chains that are expressed in varying quantities in different tissues. So far six different $\alpha$-chains have been identified and cloned [46-49]. In the GBM only $27 \%$ of the chains are not solely composed of $\alpha 1$ (IV) and $\alpha 2$ (IV). Other trimers can be formed by $\alpha 3$ (IV) and $\alpha 4(\mathrm{IV})$ and in small amounts $\alpha 5(\mathrm{IV})$ either in combination or together with $\alpha 1$ (IV) and $\alpha 2$ (IV) [50]. In diabetic nephropathy it is possible that $\alpha 1$ (IV) and $\alpha 2$ (IV) are expressed in larger quantities than in healthy kidneys [48, 51]. All $\alpha$-chains show a remarkable homology [52] with the most highly conserved parts in the end regions of the chains and the number of lysyl residues involved in glycation reactions does not vary appreciably. It has been reported that there are regions on the $\mathrm{NC1}$ domain in which all chains differ in amino acid composition and that these regions may have a role in homo dimerisation of the $\alpha$-chains [53]. In contrast, a striking similarity can be observed for the interspaced cross-linking cystein-residues in the otherwise strictly triple-helically $7 \mathrm{~S}$-domain. Therefore, it seems that triple-helicity of collagen IV isolated from different human tissues is comparable. In contrast, a $13 \%$-decrease in triple helicity as well as an appreciable difference in thermal transitions profiles, as seen in our experiments, indicates a severe disturbance of molecular integrity although the mechanism by which the thermal stability of collagen IV as well as other collagen types is reduced, can, as yet, not be explained.

The loss in triple-helical conformation of the $7 \mathrm{~S}$ domain as well as the central triple-helical domain and the formation of non-physiological oligomers may be of pathophysiological importance for the molecular basis of diabetic complications as the intact triple-helical conformation of collagen is important for a variety of functions. Self-aggregation to the collagen IV-network may be a function of the terminal domains, whereas binding of ligands, e.g. laminin and heparansulphate-proteoglycan [54-56] and interaction with adjacent cells $[57,17]$ can be attributed to the central triple-helical domain which is also a target for glycoxidative reactions. The impairment of one or some of these functions of collagen IV might be responsible for the decrease in renal performance in incipient diabetes mellitus [58].

Our data provide the first evidence for non-enzymatic modification on the 7S domain and the NC1 domain of collagen IV in the GBM of patients with diabetes mellitus similar to those reported for these domains after glycation in vitro by Raabe et al. [21] and Tsilibary et al. [30]. The effects on protein structure and stability, however, seem to be more severe in vivo than in vitro and have an impact on their structural integrity. These findings underline the importance of glycation as a possible pathogenetic principle for the onset and progression of diabetic microangiopathy and in particular for diabetic nephropathy. 


\section{References}

1. Baynes JW, Monnier KM (1989) The Maillard Reaction in Aging, Diabetes and Nutrition, A. Liss, New York

2. Wolff S, Jiang ZY, Hunt JV (1991) Protein glycation and oxidative stress in diabetes and aging. Free Radic Biol Med 10: 339-352

3. Brownlee M, Cerami A, Vlassara H (1988) Advanced glycosylation end products in tissue and the biochemical basis of diabetic complications. N Engl J Med 318: 1315-1321

4. Reiser KM (1991) Non-enzymatic glycation of collagen in aging and diabetes. Pro Soc Exp Biol Med 196: 17-29

5. Sell DR, Monnier VM (1990) Endstage renal disease and diabetes catalyse the formation of a pentose-derived cross-link from ageing human collagen. J Clin Invest 85: 380-384

6. Sell DR, Lapolla A, Odetti P, Fogarty J, Monnier VM (1992) Pentosidine formation in skin correlates with severity of complications in individuals with long-standing IDDM. Diabetes 41: 1286-1292

7. Knecht R, Leber R, Hasslacher C (1987) Degradation of glomerular basement membrane in Diabetes I. Susceptibility of diabetic and nondiabetic basement membrane to proteolytic degradation of isolated glomeruli. Res Exp Med (Berl) 187: 323-328

8. Robins SP, Bailey AJ (1972) Age-related changes in collagen: the identification of reducible lysine-carbohydrate condensation products. Biochem Biophys Res Commun 48: 76-84

9. Monnier VM, Cerami A (1983) Nonenzymatic glycosylation and browning of proteins in vivo. In: Waller GR, Feather MS, (eds) The Maillard reaction in foods and nutrition. Symposium Series No 215, American Chemical Society, Washington, pp 431-439

10. Eble AS, Thorpe SR, Baynes JW (1983) Nonenzymatic glucosylation and glucose-dependent cross-linking of protein. J Biol Chem 258: 9406-9412

11. Brownlee M, Vlassara H, Kooney A, Cerami A (1986) Inhibition of glucose-derived protein cross-linking and prevention of early diabetic changes in glomerular basement membrane by aminoguanidine. Diabetes 35 [Suppl 1]:42A

12. Granhee SK, Monnier VM (1991) Mechanism of formation of the Maillard protein cross-link Pentosidine. J Biol Chem 266: 11649-11653

13. Sell DR, Monnier VM (1989) Structure elucidation of a senescence cross-link from human extracellular matrix. J Biol Chem 264: 21597-21602

14. Nakamura K, Nakazawa Y, Ienaga K (1997) Acid-stable fluorescent advanced glycation end products: vesperlysines $\mathrm{A}, \mathrm{B}$, and $\mathrm{C}$ are formed as cross-linked products in the Mallard reaction between lysine or proteins with glucose. Biochem Biophys Res Commun 232: 227-230

15. Wells-Knecht KJ, Brinkmann E, Wells-Knecht MC et al. (1996) New markers of Mallard reaction damage to proteins. Nephrol Dial Transplant 11 [Suppl 5] 41-47

16. Monnier VM, Nagaraj RH, Potero-Otin M et al. (1996) Structure of advanced Mallard reaction products and their pathological role. Nephrol Dial Transplant 11 [Suppl 5] 20-26

17. Kent MJC, Light ND, Bailey AJ (1985) Evidence for glucose-mediated covalent cross-linking of collagen after glycosylation in vitro. Biochem J 225: 745-752

18. Bailey AJ, Sims TJ, Avery NC, Halligan EP (1995) Non-enzymatic glycation of fibrous collagen: reaction products of glucose and ribose. Biochem J 305: 385-390
19. Taneda S, Monnier VM (1994) ELISA of Pentosidine, an advanced Glycation End Product, in Biological Specimens. Clin Chem 40: 1766-1773

20. Shaw SM, Crabbe MJC (1994) Monitoring the progress of non-enzymatic glycation in vitro. Int $\mathbf{J}$ Pept Protein Res 44: 594-602

21. Raabe H-M, Molsen H, Mlinaric S-M et al. (1996) Biochemical alterations in collagen IV induced by in vitro glycation. Biochem J 319: 699-704

22. Yang L, Rui H, Mosler S, Notbohm H, Sawaryn A, Müller PK (1993) Collagen II from articular cartilage and anulus fibrosus. Structural and functional implications of tissue specific posttranslational modifications of collagen molecules. Eur J Biochem 213: 1297-1302

23. Bailey AJ, Sims TJ, Light N (1984) Cross-linking in type IV collagen. Biochem J 218: 713-723

24. Timpl R, Wiedemann H, van Delden V, Furthmayr H, Kühn K (1981) A network model for the organization of type IV collagen molecules in basement membranes. Eur J Biochem 120: 203-211

25. Ristelli J, Bächinger HP, Engel J, Furthmayr H, Timpl R (1980) 7S-Collagen: characterization of an unusual basement membrane structure. Eur J Biochem 108: 239-250

26. Weber S, Engel J, Wiedemann H, Glanville R, Timpl R (1984) Subunit structure and assembly of the globular domain of basement membrane collagen type IV. Eur J Biochem 139: 401-410

27. Timpl R (1986) Recent advances in the biochemistry of glomerular basement membrane. Kidney Int 30: 293-298

28. Yurchenco PD, Ruben GC (1987) Basement membrane structure in situ: evidence for lateral association in the type IV collagen network. J Cell Biol 105: 2559-2568

29. Yurchenco PD, Ruben GC (1988) Type IV collagen lateral associations in the EHS tumor matrix: comparison with amniotic and in vitro networks. Am J Pathol 132: 278-291

30. Tsilibary EC, Charonis AS, Reger LA, Wohlhueter RM, Furcht LT (1988) The effect of nonenzymatic glucosylation on the binding of the main noncollagenous $\mathrm{NC1}$ domain to type IV collagen. J Biol Chem 263: 4302-4308

31. Anderson SS, Tsilibary EC, Charonis A (1993) Nonenzymatic glycosylation-induced modification of intact bovine kidney tubular basement membrane. J Clin Invest 92: 3045-3052

32. Tarsio JF, Reger LA, Furcht LT (1987) Decreased interaction of fibronectin, type IV collagen, and heparin, due to nonenzymatic glycation. Implications for diabetes mellitus. Biochemistry 26: 1014-1020

33. Tarsio JF, Reger LA, Furcht LT (1988) Molecular mechanisms in basement membrane complications of diabetes. Alterations in heparin, laminin and type IV collagen association. Diabetes 37: 532-539

34. Brownlee M, Pongor S, Cerami A (1983) Covalent attachment of soluble proteins by nonenzymatically glycosylated collagen. J Exp Med 158: 1739-1744

35. Sensi M, Tanzi P, Bruno MR et al. (1989) Nonenzymatic glycation of isolated human glomerular basement membrane changes ist physicochemical characteristics and binding properties. Nephron 52: 222-226

36. Spiro R (1966) Studies on the renal glomerular basement membrane. J Biol Chem 242: 1915-1922

37. Laemmli U (1970) Cleavage of structural proteins during assembly of the head of the bacteriophage T4. Nature 227: 680-685

38. Towbin H, Staehelin T, Gordon J (1979) Electrophoretic transfer of proteins from polyacrylamid gels to nitrocellulose sheets: Procedure and some applications. Proc Natl Acad Sci USA 76: 4350-4354 
39. Monnier VM, Vishwanath BA, Frank KE, Elmets CA, Dauchot P, Kohn RR (1986) Relation between complications of Type I diabetes mellitus and collagen-linked fluorescence. N Engl J Med 314: 403-408

40. Borch-Johnsen K, Kreiner G (1987) Proteinuria: value as predictor of cardiovascular mortality in insulin dependent diabetes mellitus. BMJ 294: 1651-1654

41. Bailey AJ, Sims TJ, Avery NJ, Miles CA (1993): Chemistry of collagen cross-links: glucose-mediated covalent crosslinking of type IV collagen in lens capsules. Biochem $\mathbf{J}$ 296: 489-496

42. Charonis AS, Tsilibary EC (1992) Structural and functional changes of laminin and type IV collagen after nonenzymatic glycation. Diabetes 41 [Suppl 2] 49-51

43. Shimomura H, Spiro R (1987) Studies on macromolecular components of human glomerular basement membrane and alterations in diabetes. Diabetes 36: 374-381

44. Tsilibary EC, Charonis AS (1986) The role of the main noncollagenous domain (NC1) in type IV collagen self-assembly. J Cell Biol 103: 2467-2473

45. Trueb B, Flückinger R, Winterhalter KH (1984) Nonenzymatic glycosylation of basement membrane collagen in diabetes mellitus. Collagen Res 4: 239-251

46. Hostikka SL, Tryggvason K (1988) The complete primary structure of the 2 chain of human type IV collagen and comparison with the 1(IV) chain. J Biol Chem 263: 19488-19493

47. Mariyama M, Leinonen A, Mochizuki T, Tryggvason K, Reeders ST (1994) Complete primary structure of the human $\alpha(\mathrm{IV})$ collagen chain. Coexpression of the $\alpha 3(\mathrm{IV})$ and $\alpha 4(\mathrm{IV})$ chains in human tissues. J Biol Chem 269: 23013-23017

48. Leinonen A, Mariyama M, Mochizuki T, Tryggvason K, Reeders ST (1994) Complete primary structure of the human type IV collagen $\alpha 4(\mathrm{IV})$ chain. J Biol Chem 269: 26172-26177
49. Zhou J, Hertz JM, Leinonen A, Tryggvason K (1992) Complete amino acid sequence of the human $\alpha 5$ (IV) collagen chain and identification of a single-base mutation in exon 23 converting glycine 521 in the collagenous domain to cystein in an Alport syndrome patient. J Biol Chem 267: 12475-12481

50. Zhou J, Ding M, Zhao Z, Reeders ST (1994) Complete primary structure of the sixth chain of basement membrane collagen, $\alpha 6(I V)$. J Biol Chem 269: 13193-13199

51. Langeveld JP, Wieslander J, Timoneda J et al. (1988) Structural heterogeneity of the noncollagenous domain of basement membrane collagen. J Biol Chem 263 (21): $10481-10488$

52. Gunwar S, Saus S, Noelken ME, Hudson BG (1990) Glomerular basement membrane: identification of a fourth chain, $\alpha 4$, of type IV collagen. J Biol Chem 265: 5466-5469

53. Kühn K (1994) Basement membrane (type IV) collagen. Matrix Biol 14: 439-445

54. Woodley DT, Rao CN, Hassel JR, Liotta LA, Martin GR, Kleinmann HK (1983) Interactions of basement components. Biochim Biophys Acta 761: 278-285

55. Laurie GW, Bing JT, Kleinmann HK, Hassel JR, Aumailley M, Martin GR, Feldmann J (1986) Localization of binding site for laminin, heparan sulfate proteoglycan and fibronectin on basement membran (type IV) collagen. J Mol Biol 189: 205-216

56. Timpl R (1989) Structure and biological activity of basement membrane proteins. Eur J Biochem 180: 487-502

57. Aumailley M, Timpl R (1986) Attachment of cells to basement membrane collagen type IV. J Cell Biol 103: $1569-1575$

58. Mogensen CE, Chachati A, Christensen CK et al. (1986) Microalbuminuria: an early marker of renal involvement in diabetes. Uremia Invest 9: 85-95 